\title{
A PERSUASÃO TEXTUAL NAS TENTATIVAS DE PERSUADIR DO DEBATE POLÍTICO PRESIDENCIAL BRASILEIRO
}

\author{
Romildo Barros da SILVA (DD \\ Universidade Federal de Alagoas (UFAL) \\ Maria Francisca Oliveira SANTOS (DD \\ Universidade Federal de Alagoas (UFAL) \\ Janyellen Martins SANTOS (D) $\boldsymbol{M}$ \\ Universidade Federal de Alagoas (UFAL)
}

\section{OPEN ACCESS}

EDITADO POR

- Miguel Oliveira, Jr. (UFAL)

- René Almeida (UFS)

REVISADO POR

- Evandro de Melo Catelão (UTFPR)

- Rosalice Botelho (NOVA)

SOBRE OS AUTORES

- Romildo Barros da Silva

Escrita - Análise e Edição.

- Maria Francisca Oliveira Santos Supervisão.

- Janyellen Martins Santos

Escrita - Análise e Edição.

DATAS

- Recebido: 30/01/2020

- Aceito: 30/03/2020

- Publicado: 03/11/2020

\section{COMO CITAR}

SILVA, R. B.; SANTOS, M. F. O.

SANTOS, J. M. (2020). A persuasão

textual nas tentativas de persuadir do debate político presidencial brasileiro.

Cadernos de Linguística,

v. 1, n. 2, p. 01-17.

\section{RESUMO}

O presente artigo analisa as tentativas de persuadir no debate político televisionado das eleições presidenciais brasileiras de 2014. Esse evento retórico-linguístico é sugerido por meio da presença de dois elementos retóricos nas argumentações dos debatedores. Essa dupla persuasiva se constitui pelo ethos discursivo e pelos argumentos persuasivos. Os referencias teóricos utilizados foram: Aristóteles (2011), Baver e Gaskell (2015), Costa (2009), Fiorin (2015), Marcuschi (2008), Meyer (2007), Perelman e Olbrechts-Tyteca (2014), Reboul (2004), Souza (2001), Silva e Santos (2019), entre outros. A partir das discussões, compreendeu-se que a persuasão está nos textos do cotidiano, principalmente nos da esfera política, como o debate. O trabalho seguiu uma linha qualitativa, segundo a qual as análises foram feitas em processo. Diante disso, notou-se como as tentativas de persuadir revelam o funcionamento persuasivo desse gênero, no qual os debatedores tentam promover suas imagens discursivas, desvalorizando a do seu oponente e, para tanto, fundamentam suas teses por meio de argumentos que movam seu auditório social. Além disso, esses argumentos, nos fragmentos 
estudados, se amparam em teses verossímeis. Portanto, o debate e a persuasão se realizam mediante acordos e argumentos, comprovando que as práticas de linguagem atuam em movimentos interativos e, por isso mesmo, dependem de negociação.

\section{ABSTRACT}

This article analyzes attempts to persuade the televised political debate of the Brazilian presidential elections of 2014. This rhetorical-linguistic event is suggested through the presence of two rhetorical elements in the debaters' arguments. This persuasive double is constituted by discursive ethos and persuasive arguments. The theoretical references used were: Aristotle (2011), Baver and Gaskell (2015), Costa (2009), Fiorin (2015), Marcuschi (2008), Meyer (2007), Perelman and Olbrechts-Tyteca (2014), Reboul (2004), Souza (2001), Silva and Santos (2019), among others. From the discussions, it was understood that persuasion is in everyday texts, especially in the political sphere, such as the debate. The work followed a qualitative line, according to which the analyzes were made in process. Given this, it was noted how attempts to persuade reveal the persuasive functioning of this genre, in which debaters try to promote their discursive images, devaluing that of their opponent and, to this end, substantiate their theses through arguments that move their social audience. Moreover, these arguments, in the studied fragments, are supported by credible theses. Therefore, debate and persuasion take place through agreements and arguments, proving that language practices work in interactive movements and, therefore, depend on negotiation.

\section{PALAVRAS-CHAVE}

Debate Político; Persuasão Textual; Tentativas de Persuadir.

\section{KEYWORDS}

Political Debate; Textual Persuasion; Attempts to Persuade. 


\section{INTRODUÇÃO}

Este artigo tem por objetivo analisar as tentativas de persuadir no debate político televisivo das eleições presidenciais brasileiras de 2014. Essas tentativas ocorrem por meio de um fenômeno retórico-linguístico aqui denominado de persuasão textual, uma vez que é, a partir do texto e suas nuances, que a ação persuasiva surge. Para delimitar a análise retórica e textual, foram levantados pressupostos teóricos sobre a projeção de ethos e os argumentos utilizados pelos debatedores/retores. A partir disso, fez-se a análise de três tentativas de persuadir, seguindo os métodos da pesquisa qualitativa com texto e retórica, fundamentados em Baver e Gaskell (2015).

Dessa observação, constatou-se que o acordo prévio é criado discursivamente durante o debate televisivo. Além disso, essa negociação trata dos valores aceitos por grande parte do auditório televisivo, principalmente aqueles considerados indecisos. Entretanto, muitas dessas dúvidas que o auditório tem são sanadas no intercurso do debate, já que, além de ser persuasivo, o debate é um gênero oral (MARCUSCHI, 2008) de caráter, ocasionalmente, informacional, visto que contribui para informar seu público. Essas informações apresentadas no debate são, por sua vez, os fatos sociais críveis por cada debatedor e seu provável auditório social.

O trabalho possui duas seções teóricas: a primeira versa sobre o debate político como gênero textual, mas que está sediado na democracia; a segunda explica sobre as tentativas de persuadir, que são constituídas pela projeção do ethos dos debatedores, por argumentos persuasivos e pela negociação do acordo prévio entre debatedor e auditório social. As análises, os resultados e a conclusão são as últimas seções deste artigo. Todas as discussões teóricas e as análises aqui realizadas estão ancoradas nos seguintes autores: Aristóteles (2011), Amossy (2011), Fiorin (2015), Marcuschi (2008), Maingueneau (2008), Meyer (2007), Perelman e Olbrechts-Tyteca (2014), Reboul (2004), Souza (2001) e Silva e Santos (2019).

Além de discutir os pressupostos teóricos desses estudiosos, este trabalho relata uma das etapas do projeto de pesquisa de doutorado denominado "análise retórico-textual dos argumentos do gênero debate político: atos de persuadir fundados no acordo social”, que está sendo desenvolvido no Programa de Pós-Graduação em Linguística e Literatura (PPGLL/UFAL). Portanto, este recorte de pesquisa tratou de responder a alguns questionamentos emanados do citado projeto, tais como: Por que os argumentos se situam no contraditório e na projeção de ethos? Como o ethos discursivo (MAINGUENEAU, 2008) ${ }^{1}$ é

1 "O ethos de um discurso resulta da interação de diversos fatores: ethos pré-discursivo, ethos discursivo (ethos mostrado), mas também os fragmentos do texto nos quais o enunciador evoca sua própria enunciação (ethos 
construído no debate político televisivo? Essas indagações foram explicadas nas análises e na conclusão deste artigo.

\section{DEBATE POLÍTICO TELEVISIVO}

Tratar uma manifestação linguística como gênero requer, antes de tudo, uma abordagem empírica sobre uma categoria de uso da língua. Uma dessas abordagens estabelece que o gênero debate é uma prática de linguagem que tem por meta a discussão de temas controversos e, geralmente, há trocas verbais entre dois ou mais debatedores, um ou mais moderadores, controlando as regras e um público (plateia, assessores, telespectadores etc.). Com essa definição, pode-se evidentemente compreender o debate como: um gênero de natureza argumentativa, devido às suas discussões contraditórias; um gênero interativo, por causa da alternância de turnos de fala; um gênero regrado, (COSTA, 2009) uma vez que seu planejamento e suas regras são característicos, e um gênero público, já que seu alvo é cativar o público, e os assuntos são do interesse do auditório social.

Essa conceituação torna-se ainda mais ampla ao conceber que o gênero que está em análise é o debate político presidencial televisivo. Assim, o aspecto político endossa a abordagem de gênero argumentativo e público, afinal fazer política é lidar com as dinâmicas de uma sociedade democrática, que justamente é a única que possibilita e promove debates. Além disso, pelo fato de ser presidencial - sabe-se que a relevância social e midiática é notória, já que a escolha via eleições do representante do Poder Executivo de um país tem caráter primordial nas tarefas de todo cidadão. O jornalismo, juntamente com o suporte televisivo, faz com que o gênero se popularize e seja divulgado nos mais diversos meios de comunicação acessíveis à massa populacional. Diante disso, reconhece-se que o debate político sobrevive em sociedades democráticas e que, de fato, a mídia possibilita seu acesso aos telespectadores e demais interessados.

Outras abordagens sobre o debate político televisivo acabam concordando com os postulados ora apresentados; é o que se percebe em Braga (2006) e Kerbrat-Orecchioni (1990). A primeira afirma: "o debate político televisivo é uma categoria discursiva suficientemente específica e delimitável, com uma estrutura e funcionamento particulares" (BRAGA, 2006, p. 3).

Kerbrat-Orecchioni, por sua vez, verifica que

dito) - diretamente ("é um amigo que lhes fala") ou indiretamente, por meio de metáforas ou de alusões a outras cenas de fala, por exemplo." (MAINGUENEAU, 2008, p. 18). Entretanto, de maneira geral, o ethos retórico "consiste em causar boa impressão pela forma como se constrói o discurso, a dar uma imagem de si capaz de convencer o auditório, ganhando sua confiança.”(MAINGUENEAU, 2008, p. 11). 
enquanto interação específica, o debate é, portanto, uma discussão em que se verifica um confronto de opiniões, mas que possui um carácter mais organizado, desenrolando-se dentro de um quadro "pré-fixado", ou seja, o seu quadro comunicativo [...] e algumas coordenadas são prédeterminadas. (KERBRAT-ORECCHIONI, 1990 apud BRAGA, 2006, p. 4, itálicos da autora).

A linguista francesa salienta, desse modo, que o planejamento e o embate de opiniões caracterizam esse gênero textual. Além disso, "a sua natureza política conduz ao discurso polêmico, espaço de argumentação e dialogismo." (BRAGA, 2006, p. 1). Entretanto, essas polêmicas oriundas do debate não surgem de per si, afinal, "o debate tem regras, possui uma espécie de código que consiste em jogar/cooperar de modo competitivo.", (BRAGA, 2006, p. 5). Essa negociação acirrada deve sempre ser moderada pelas regras combinadas previamente, pois os participantes devem ter papéis equilibrados e simétricos, conforme Braga (2006) e Kerbrat-Orecchioni (1990).

Desse modo, o debate político na televisão surge de necessidades (divulgar as propostas políticas) e atividades socioculturais (eleições), de acordo com Marcuschi (2008). Ademais, o debate político, sendo um gênero textual, instaura o contraditório em suas argumentações de maneira diversificada, uma vez que seu suporte e sua finalidade são alinhados pelos interesses do político (debatedor), do canal televisivo (jornalismo) e, principalmente, do público (auditório social). O debate político presidencial televisivo faz parte, portanto, de uma situação comunicativa planejada (debate regrado) que visa à discussão de temas relevantes e, para tanto, move diversificados elementos persuasivos. Três desses elementos serão detalhados na seção seguinte.

\section{TENTATIVAS DE PERSUADIR}

A expressão tentativa de persuadir se justifica por dois fatores: o primeiro é que, neste trabalho, não foram adotados métodos de percepção das reações do público, dado à universalidade do auditório do debate e o próprio alinhamento da pesquisa, que se direciona para os elementos em imanência no texto; o segundo fator é que toda ação textual-discursiva é um empreendimento persuasivo, ou seja, não se pode ter garantias que, de fato, somente determinados recortes textuais foram capazes de mover o auditório para uma mudança de comportamento ou uma ação aos moldes de quem argumentou. Assim, a partir das transcrições dos dados orais do debate, juntamente com os comentários da transcrição quanto aos elementos não verbais, foram interpretadas as ações retóricas dos debatedores das eleições presidenciais brasileiras de 2014

O que se sabe de antemão, dada a execução de pesquisas anteriores pelo Grupo de Estudos do Texto e da Leitura (GETEL/UFAL), é que as tentativas de persuadir se manifestam por meio de argumentos que, por sua vez, se tipificam em dois grandes 
grupos/objetivos: aqueles que visam contrariar as teses e opiniões adversárias e os que objetivam a promoção e/ou a desqualificação do ethos. Esses dois procedimentos das tentativas de persuadir serão detalhados nas próximas subseções.

\subsection{ETHOS RETÓRICO-DISCURSIVO}

O questionamento relacionado ao fato da maneira como o debatedor deve se portar diante de um público que ele pretende persuadir gerou e tem gerado estudos sobre argumentação e manipulação no discurso. $O$ interesse deste artigo reside no aspecto da argumentação que pode ser fortalecida pela imagem que o enunciador/retor projeta ao discursivizar, o que pensa e defende, isto é, na criação de seu ethos, que tem, notadamente, caráter duplo: retórico e discursivo.

O ethos retórico/discursivo² diz respeito ao orador (REBOUL, 2004), entretanto esse termo não é de domínio individual de quem argumenta, uma vez que, em uma discussão polêmica, ocorre sempre uma negociação/troca de valores, de informações e de ideologias. Nesse sentido, o ethos é interindividual, pois o público enxerga o ethos do orador a partir daquilo que ele enuncia, mas também por meio daquilo que o próprio público pretendia ver naquele retor. Nessa descrição, está evidente o aspecto emotivo desse meio de persuasão proposto por Aristóteles (2011).

Além disso, se, de fato, o ethos surge de um compartilhamento de virtudes entre o retor e o auditório, ele é equipado por valores e crenças de cada comunidade. Nisso, pode-se associar o ethos ao comportamento discursivo do enunciador que é influenciado pela cultura local. Dotado desses valores culturais, o ethos de um orador será aceito com mais facilidade pelo público que dispõe atenção a esse retor, que poderá progredir na sua argumentação e, possivelmente, persuadir esse auditório.

No entanto, essa é uma tarefa complexa, pois o debatedor/retor deseja que

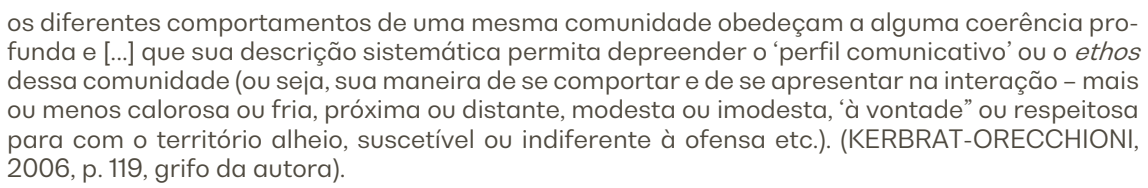

Com tal definição, o ethos discursivo do debatedor político é mediado pelas impressões que ele tem do seu auditório (comunidade). Assim, comprova-se que esse meio de persuadir depende sempre do pathos, isto é, as paixões e valores do auditório, uma vez que são elas que irão compor parte do ethos do debatedor persuasivo.

2 O ethos no debate político é construído pelo debatedor ao formar uma imagem favorável de sua pessoa destinada a lhe conferir poder e influência, por isso tem sua natureza discursiva, (AMOSSY, 2011). 
Aristóteles (2011) destaca bem quanto a essa postura moral e ética que os retores devem ter; afinal, a retórica é um bem útil, porém, quando mal utilizada, para defender causas injustas, por exemplo, ela se torna danosa. O responsável direto disso ou daquilo que se faz com a técnica persuasiva é sempre o retor (ARISTÓTELES, 2011).

Diante disso,

\begin{abstract}
o ethos designa, portanto, uma postura moral, que deve estar presente por quem argumenta. Desse modo, a ética de um discurso contribui para efetivação de um ethos, pois além de demonstrar a sinceridade, o retor deve estabelecer seus pontos de vista de uma forma que não prejudique seus argumentos, mas sempre almeje a confiança do auditório, que necessita de uma prática moral. (SILVA; SANTOS, 2019, p. 33).
\end{abstract}

Ainda no escopo dessas características morais, as quais o debatedor deve projetar em seu ethos durante uma tentativa de persuadir, têm-se as seguintes: prudência (phrónesis), integridade (aréte) e agradabilidade (eunóia) (MEYER, 2007); virtude (ARISTÓTELES, 2011); confiança, bom senso, sabedoria prática e benevolência (FIORIN, 2015).

Com essas considerações, de acordo com Silva e Santos (2019), nota-se que o ethos se configura por meio de sentimentos projetados e demonstrados. Contudo, todas essas virtudes emanadas por esse meio de persuadir são detectadas pelo discurso e não se isolam na consciência do enunciador, ou seja, não se trata dos aspectos psicológicos de cada retor, mas sim dos traços discursivos de suas enunciações quando marcam seus posicionamentos numa discussão contraditória. A partir disso, Fiorin (2015. p. 70) confirma: "a análise do éthos do enunciador nada tem de psicologismo [...] trata-se de apreender um sujeito construído pelo discurso", por isso, "o éthos é uma imagem do autor, não é o autor real; é um autor discursivo, um autor implícito.".

Sobre esse aspecto da projeção do ethos no discurso retórico (logos), a seguir serão explicados alguns tipos de argumento, que realmente demarcam a ação retórica, por isso aqui são nomeados de argumentos persuasivos.

\title{
2.2. ARGUMENTOS PERSUASIVOS
}

Argumento é um esquema que permite defender/refutar uma tese (SILVA; SANTOS, 2019). Os gregos antigos entendiam que argumentar era uma prática da natureza humana, por isso era essencial defender-se com palavras, evitando a força/violência para conseguir algo. Os argumentos, portanto, servem para um objetivo específico de cada orador, porém dada a infinidade de propósitos com os quais a sociedade lida, os argumentos também são numerosos. Diante disso, neste recorte de trabalho, após a análise prévia do corpus, deuse ênfase apenas naqueles argumentos ditos persuasivos para o debate político, a exemplo 
dos de natureza do contraditório ${ }^{3}$, como o de incompatibilidade, retorsão, autofagia e antimodelo, e, também, os que enfatizam a projeção do ethos, como o do sacrifício, modelo, quantidade e regra de justiça.

Além desses argumentos citados, os argumentos quase-lógicos (PERELMAN; OLBRECHTS-TYTECA, 2014) também foram estudados, uma vez que eles apresentam uma notável saliência nos debates políticos de segundo turno, conforme Silva e Santos (2019). Esses argumentos são denominados de quase-lógicos pela sua semelhança com a lógica formal e a demonstração. Por esse motivo, a pessoa que faz uso desse tipo de argumento "se prevalece [...] do prestígio do raciocínio rigoroso" (PERELMAN; OLBRECHTS-TYTECA, 2014, p. 220). Dessa maneira, seu argumento será superior porque pode vir a produzir um efeito mais persuasivo.

Existem dois grupos de argumentos quase-lógicos: "os que apelam para estruturas lógicas - contradição, identidade total ou parcial, transitividade" e "os que apelam para relações matemáticas - relação da parte com o todo, do menor com o maior, relação de frequência." (PERELMAN; OLBRECHTS-TYTECA, 2014, p. 220). A partir desses esquemas argumentativos, surgem outros argumentos já conhecidos, como a retorsão, a ironia, a regra de justiça etc.

A seguir, há um quadro com os tipos de argumento aqui analisados e suas respectivas funções:

\begin{tabular}{|l|l|}
\hline \multicolumn{1}{|c|}{ Argumento } & \multicolumn{1}{c|}{ Função } \\
\hline Retorsão & $\begin{array}{l}\text { Retomar o argumento do outro, mostrando que } \\
\text { ele está contra a sua própria argumentação. }\end{array}$ \\
\hline Autofagia & $\begin{array}{l}\text { Mostrar que o enunciado do outro se destrói } \\
\text { por si mesmo. }\end{array}$ \\
\hline Antimodelo & Determinar o que ou quem não se deve imitar. \\
\hline Sacrifício & $\begin{array}{l}\text { Estabelecer o valor de uma coisa/causa pelos } \\
\text { sacrifícios que são ou serão feitos por ela. }\end{array}$ \\
\hline Modelo & Imitar bons exemplos de pessoas e ações. \\
\hline Quantidade & $\begin{array}{l}\text { Sugerir números e estatísticas para defender } \\
\text { que o que é maior é melhor. }\end{array}$ \\
\hline Regra de justiça & $\begin{array}{l}\text { Tratar da mesma maneira seres da mesma ca- } \\
\text { tegoria. }\end{array}$ \\
\hline
\end{tabular}

Quadro 1. Tipos de argumento. Fonte: Adaptado de Perelman e Olbrechts-Tyteca (2014) e Reboul (2004).

\subsection{ACORDO SOCIAL E FATOS}

O acordo prévio é a condição primordial para que a argumentação aconteça. Sem esse acordo, o retor não terá atenção nem interesse do público; será um discurso produzido a esmo. Assim, esse acordo deve ser feito de alguma forma, seja de modo explícito ou disfarçado no discurso; e, para iniciar essa negociação com o público, o debatedor deve se apoiar

3 Os argumentos de natureza do contraditório situam na noção de incompatibilidade proposta por Perelman e Olbrechts-Tyteca (2014) 
em fatos. Desse modo, ambas as categorias (acordo e fatos) se situam no meio social, no público, e suas vivências, portanto, se encontram no pathos do auditório social.

Dessa forma, para que a tentativa de persuadir possa ser completa, os retores devem se apropriar dos fatos sociais para, a partir deles, tentar construir um acordo inconsciente e persuadir o público televisivo. Esses fatos produzidos em sociedade mobilizam os acordos, os argumentos e as ideologias. Nesse sentido, "os fatos sociais são as coisas que as pessoas acreditam que sejam verdadeiras [...]. As pessoas, então, agem como se esses fatos fossem verdades." (BAZERMAN, 2005, p. 23-24).

Isso não implica que o cidadão comum acredite apenas no que for conveniente; afinal, as pessoas que constituem o auditório universal ${ }^{4}$ são movidas por fatos - aquilo que é verossímil, aceitável e provável, ou seja, tudo que diz respeito à argumentação. Por essa razão, os fatos sociais estão imbricados nos argumentos contraditórios e, sobretudo, persuasivos do gênero debate.

Além disso, o fato social é o único elemento visível do acordo prévio do debate político, pois o retor, ao afirmar determinado fato, que o debatedor adversário empregou toda a sua família em cargos comissionados, por exemplo, para o público televisivo, pode ser aceito, se for do conhecimento desse auditório, ou recusado caso ele saiba que esse fato não proceda ou gere dúvidas. Quando um fato incutido em um argumento é aceito pelo público, ele o toma como verdade. Esse, portanto, é o ponto de partida para a persuasão, assim como também é um dos indícios do pathos que se revela na argumentação política.

Dessa maneira, "na argumentação a palavra ou [...] as premissas, as razões invocadas e as provas fornecidas pelo orador não têm a força nem o rigor do cálculo matemático, pelo que nunca poderiam conduzir à evidência, à necessidade ou à verdade única." (SOUZA, 2001, p. 151). Diante disso, um discurso persuasivo não carece da demonstração para se efetivar, basta que, de certo modo, esteja em concordância com os argumentos verossímeis e aceitos pelo auditório social. ${ }^{5}$

\subsection{PERSUASÃO TEXTUAL/DISCURSIVA}

Os argumentos, o ethos, o acordo e os fatos sociais são percebidos somente por intermédio do texto. Por essa razão, a persuasão tem por natureza a linguagem humana e reside em todo texto que tenha potencial persuasivo, daí decorre a concepção de entendê-la como

4 O auditório universal é heterogêneo e quem argumenta se adapta às visões de mundo do seu público e, por sua vez, se apoiam nas teses aceitas por este público naquele momento. (PERELMAN; OLBRECHTS-TYTECA, p. 34-35, 2014).

5 O auditório social é o alvo do enunciado que se forma entre dois indivíduos socialmente organizados, e, na ausência de um interlocutor real, ele é ocupado, por assim dizer, pela imagem do representante médio daquele grupo social ao qual o falante pertence. (VOLÓCHINOV, 2017, p. 204) 
persuasão textual/discursiva. Nesse sentido, o texto nunca deve estar dissociado do discurso, por isso texto e discurso estão amalgamados nessa concepção.

A persuasão como fenômeno retórico e linguístico "é tarefa delegada aos retores que vão alinhar sentimentos que permitam mover ações de um determinado auditório." (SILVA; SANTOS, 2019, p. 59). O espaço em que se expressam sentimentos e se defendem ideologias é o texto/discurso, por isso, a persuasão sempre o terá como suporte. Além disso, as ações no mundo são movidas por discursos, que fazem a gestão sobre o que é mais ou menos preferível, provável e aceitável. Assim, pode-se compreender que, de fato, o texto move ações na sociedade, independente do gênero textual que ele esteja projetando.

Desde a antiguidade grega, a persuasão era tida como objetivo dos discursos retóricos. Entretanto, "ela é mais que uma simples finalidade da ação retórica (persuadir) ou um meio de obter consentimento do outro sobre certas ideias." (SILVA; SANTOS, 2019, p. 60). A persuasão é um fenômeno de linguagem essencial para todo aquele que pretende argumentar em seu meio social, por mais que não queira admitir ou demonstrar que está persuadindo. Além disso, a persuasão seria o prêmio de quem "vence" um debate ou qualquer outra prática de linguagem argumentativa, porém para alcançá-lo não necessita revelar que o tem como meta, uma vez que "quem pretende persuadir oculta suas intenções e fatores intelectuais em prol da sua argumentação e de seu respectivo êxito" (SILVA; SANTOS, 2019, p. 60). O texto e a persuasão estão, portanto, em comunhão também nesse aspecto, pois o primeiro serve para ocultar essas intencionalidades do debatedor/retor com o fito de cumprir com a finalidade da ação de linguagem, seja ela um debate político, uma entrevista, uma conferência ou uma conversa espontânea.

\section{ANÁLISES}

Na pesquisa qualitativa, este estudo definiu como objetivo interpretar as tentativas de persuadir dos debatedores políticos das eleições presidenciais brasileiras no ano de 2014. Entretanto, para fazer tal estudo, com a ancoragem teórica da Retórica e dos Estudos Textuais, necessitou definir uma análise interpretativa, que se deu a partir dos fatos elencados nas falas dos debatedores, denominados RA (Retor A) e RB (Retor B). Assim, este estudo processual e que não faz análises quantitativas, de recorrência e comparações (BAUER; GASKELL, 2015) parte do pressuposto que, de fato, todo enunciado é argumentativo, por isso eles dão margem à análise dos recursos que evidenciam ou não atuação da Retórica no texto transcrito do debate político televisivo.

Além disso, é importante saber que "a construção de um corpus é o princípio que permite uma coleta sistemática de dados, sem seguir a lógica da amostragem estatística." (BAUER; GASKELL, 2015, p. 16). É, por isso, um princípio da pesquisa qualitativa e permite 
ser feita uma seleção conforme a significância/relevância para o que se pretende analisar. Aqui, foram selecionadas três tentativas de persuadir, contextualizadas e permitindo a compreensão da temática abordada. O foco geral está na atuação da persuasão textual/discursiva, por meio dos argumentos que favorecem a projeção de ethos e a instauração do contraditório. Os debates aqui estudados e transcritos ${ }^{6}$ são do segundo turno das eleições pelo fato de evidenciar de maneira mais precisa o contraditório.

\subsection{TENTATIVA DE PERSUADIR 1}

RA - candidato... o Brasil... é um país... que se destaca hoje no mundo... pelo fa::to de ter criado miLHÕES de empregos... nós não só criamos empregos... como também... tivemos um aumento significativo... do -- da renda... neste... mês de setembro... um e meio por cento real... o senhor concorda... com o que fala... o seu candida::to a ministro... da fazenda... que diz... que o salário mínimo está alto demais? (00:08:15 - 00:08:47. PERG. 2; DEBATE 4 - 2T). ${ }^{7}$

O Retor A inicia sua argumentação projetando valores no seu ethos discursivo, que se associa ao termo "Brasil", uma vez que esse debatedor é o candidato da situação. Assim, ao mencionar que o Brasil se destaca na criação de emprego e aumento de renda, essas ações são atribuídas ao ethos de RA.

O retor A faz uso do argumento do antimodelo, ao citar a imagem de um ministro da fazenda, que afirma que o salário mínimo está alto demais. Essa inserção do argumento do antimodelo está vinculada tanto à projeção de ethos de RA, quanto à desconstrução da imagem discursiva de RB. Além disso, o antimodelo abre espaço também para visões opostas perante o que se estabelece como alguém que não deve ser seguido, devido às suas supostas ações (PERELMAN; OLBRECHTS-TYTECA, 2014). É notável, desse modo, o quanto nessa simples enunciação estão sendo negociados fatos sociais, a respeito das ações econômicas de RA e as afirmações do provável ministro da fazenda do retor adversário.

Dessa maneira, ao construir o antimodelo, o Retor A fragiliza o ethos do seu opositor, isto é, o Retor B é alvo do argumento pelo antimodelo utilizado pelo Retor A. Essa ferramenta persuasiva é sugerida ao término da pergunta de RA: "o senhor concorda... com o que fala... o seu candida:.to a ministro... da fazenda... que diz... que o salário mínimo está alto demais?" A leitura que deveria ser feita sobre essa pergunta seria: RA, o senhor concorda com essa medida prejudicial à população que ganha salário mínimo? Em outras palavras, o Retor A quer saber se o Retor B defende o posicionamento de um possível antimodelo (ministro da fazenda) para o auditório que provavelmente está em desacordo com a opinião do ministro. 
Assim, o argumento pelo antimodelo requer, de certo modo, um acordo prévio entre retor e auditório, por isso que o Retor $\mathrm{A}$, ao conhecer que tal medida anunciada pelo ministro do opositor seria nociva ao público, faz uso do argumento do antimodelo para fragilizar o ethos de RB.

Além disso, o Retor A faz uso do argumento de quantidade em: "o Brasil... é um país... que se destaca hoje no mundo... pelo fa::to de ter criado miLHÕES de empregos"; fica evidente o quanto esse elemento retórico subsidia a projeção de virtudes do ethos do retor $A$.

Esses dois argumentos utilizados: o antimodelo e o de quantidade possuem características semelhantes no que diz respeito à simplicidade de percepção pelo público em geral, por reconhecer que uma ação/pessoa não deve ser imitada e os vultosos investimentos de um determinado candidato é um processo simples, gerando uma aceitabilidade das teses defendidas pelo debatedor que apresenta esses argumentos. Entretanto, o antimodelo se situa formalmente na contradição e tem cunho afetivo, por instruir quanto às paixões e aos valores do público.

Desse modo, o antimodelo seria um argumento que divide espaço entre racionalidade e emoção. O aspecto racional de sua construção reside na contestação de um comportamento por meio de exposição de fatos e o racional na sugestão do que é preferível para o público, apelando para condutas morais que, por sua vez, estão arraigadas na cultura do auditório social.

O argumento de quantidade é inicialmente lógico e com aspecto demonstrativo, por isso se situa nos argumentos quase-lógicos. Entretanto, essa quantificação, inevitavelmente, mexe com hierarquias em que se determina o que vale mais ou menos, por isso, apesar de lidar com números e estatísticas, o argumento de quantidade tem uma raiz no alinhamento ideológico do público para o qual foi criado. Assim, "a criação de milhões de empregos e o crescimento da renda”, não demonstra apenas cifras, mas sim uma ação que agrada o público televisivo, ou seja, o Retor A está investindo na agradabilidade do seu público ao mencionar tais ações de seu ethos.

A próxima tentativa de persuadir é a resposta à pergunta feita pelo Retor A na primeira tentativa ora analisada. Nota-se, antecipadamente, como o Retor B faz um espelhamento de alguns argumentos já construídos pelo Retor $\mathrm{A}$ e contra-argumenta utilizando os fatos sociais já apresentados e acrescenta novos para progredir e situar a sua argumentação.

\subsection{TENTATIVA DE PERSUADIR 2}

RB - candidata... não é justo colocar palavras nas bocas... de quem não está aqui anh... para respondê-la... eu tenho orgulho... enorme... do meu... candidato a ministro da fazenda... a senhora parece que não tem do seu... até porque já demitiu... o atual ministro da fazenda... mas o Brasil candidata... é visto sim pela comunidade internacional como um dos países que menos cresce na nossa região... temos uma taxa de investimentos hoje de dezesseis e meio por cento do PIB... a pior da década... porque o se::u governo afugentou os investimentos... e a inflação infelizmente está de volta... a situação do Brasil... é extremamente grave candidata... e é preciso que/o seu governo... reconheça isso... porque os merca.:dos... outros países... os brasileiros já... reconhecem... o governo do do P... e o governo da candidata D. R... fracaSSOU na condução da economia... pois nos deixará... uma inflação saindo de controle... por mais que ela não a reconheça... um crescimento pífio... fracassou na gestão 
do estado nacional... o Brasil é hoje um cemitério de obras abandonadas... inacabadas... e com sobrepreços... e FORtes denúncias de desvios... por toda a parte... e fracassou na melhoria dos nossos indicadores sociais... lamentavelmente candidata... esse é o retrato do Brasil real... não é... o retrato do Brasil da propaganda... do seu marqueteiro... mas nós... vamos muito mal na saúde... ou a senhora acha que vai bem ?... vamos mal na segurança pública... com uma omissão criminosa do Governo Federal... e vamos muito mal na educação... a senhora será... a primeira Presidente da República... pós-plano real... que deixará o país com uma inflação maior:: do que aquela que recebeu... (00:08:48 - 00:10:21. RESP. A PERG. 2; DEBATE 4 - 2T)

A resposta do Retor B, por sua vez, apresenta um argumento da regra de justiça: "não é justo colocar palavras nas bocas... de quem não está aqui anh... para respondê-la...". A regra de justiça propõe tratar situações/pessoas de forma igualitária (REBOUL, 2004). Assim, na perspectiva de RB, não é justo falar do ministro que não está no debate para defender-se (regra de justiça), já que os debatedores presentes podem dialogar, porém o referido ministro, por estar fora do debate, não pode discutir.

Ainda sobre esse fato, o Retor B projeta no futuro ministro a essência de uma pessoa especialista e responsável para ocupar o cargo de ministro da fazenda, sugerindo o argumento pelo modelo. RB ainda afirma que o candidato adversário não se orgulha do ministro que tem, já que o demitiu, o que pode ser confirmado em: "...eu tenho orguIho... enorme... do meu... candidato a ministro da fazenda... a senhora parece que não tem do seu... até porque já demitiu... o atual ministro da fazenda.../.../". Todas essas afirmações e proposições são formuladoras das imagens discursivas dos candidatos do debate. Assim, toda estratégia de argumentação utilizada contribui para a construção/desconstrução do ethos dos retores.

Ainda nesse âmbito das projeções de ethos, o Retor B faz uma associação entre o ethos de RA às referências a Brasil. Desse modo, o Brasil ou o ethos projetivo de RA perdeu investimentos e não cresceu. Na compreensão de RB, isso mostra certa incompatibilidade com o que RA havia afirmado em sua pergunta, uma vez que RA constatou: "nós não só criamos empregos... como também... tivemos um aumento significativo... do -- da renda". Com isso, apresenta-se o argumento de retorsão para desconstruir as argumentações de RA e também o seu ethos.

Esse desmonte do ethos adversário é ainda mais fortificado quando o Retor B relata enfaticamente que o governo de RA afugentou investimentos, ou seja, o Retor A, de certo modo, prejudicou o povo (pathos). Assim, os valores e disposições do auditório são movimentados nessa simples enunciação, que se torna complexa, dado que ela é situada sócio-historicamente.

Nesse viés de mobilizar as paixões do público, o Retor B tenta construir ou fortalecer um acordo com seu auditório. Isso é registrado em: "os brasileiros já... reconhecem... o governo do do P... e o governo de RA fracassou". Nisso reside também a possível ausência de prudência por parte do ethos de RA, já que o fracasso insinua que determinada pessoa falhou nos seus objetivos ou que não agiu considerando os riscos de sua ação. Essa projeção negativa do ethos adversário é destacada por meio da repetição do termo "fracassou" 
nos momentos finais da resposta de RB. A repetição, nesse caso, serviu para realçar as possíveis falhas do Retor A.

O Retor B faz também uma dissociação de noção ${ }^{8}$ entre o Brasil real e o aparente, por meio da expressão "esse é o retrato do Brasil real... não é... o retrato do Brasil da propaganda... do seu marqueteiro...". Nota-se que esse retrato diz respeito ao fracasso do governo de RA, já comentado nas falas anteriores de RB. Assim, ao inserir a dissociação entre aparência e realidade, o Retor B cria uma hierarquia de valores e propõe duas realidades distintas.

Possivelmente, ao considerarem Perelman e Olbrechts-Tyteca (2014), essa dissociação serve para excluir uma ideia incompatível. Assim, o Retor B toma como realidade e fato o que ele afirma sobre o retor adversário e, desse modo, não aceita a noção de realidade apresentada na propaganda de RA. Esse argumento de dissociação de noções, por sua vez, afeta a manifestação discursiva do ethos de RA que, como fora demonstrado, está conectado com o termo Brasil e, de acordo com os fatos mencionados por RB, não possui integridade (MEYER, 2007), visto que sua propaganda engana os eleitores.

A próxima tentativa de persuadir surge dos minutos finais do debate, quando os debatedores estão respondendo perguntas feitas pelos eleitores indecisos que faziam parte da plateia do debate político televisivo. Essas perguntas eram elaboradas previamente e os eleitores apenas liam suas perguntas caso fossem sorteadas pelo moderador. A referida pergunta versava sobre o tratamento do esgoto a céu aberto e a Eleitora Indecisa 5 (E5) indaga: O que impede de verdade os governos resolverem esse problema? O Retor B, por sua vez, comenta da terceirização de responsabilidades feita pelo governo vigente (RA) e que pretende tratar diretamente a questão do esgoto, se for eleito. Essa resposta abre espaço para a criação do primeiro argumento de RA que será analisado a seguir.

\subsection{TENTATIVA DE PERSUADIR 3}

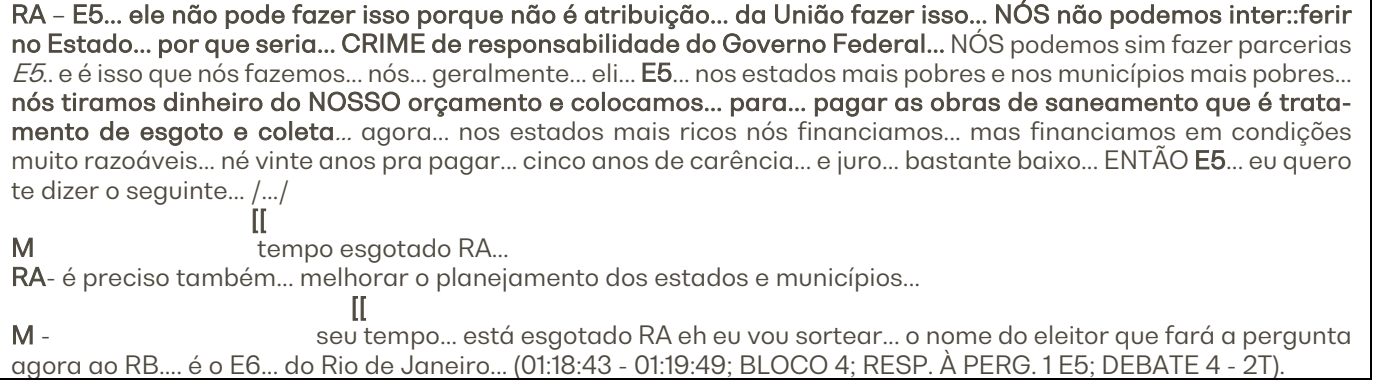

8 É um esquema argumentativo que dissocia noções em pares hierarquizados e, disso, surgem duas realidades (aparente/verdadeira). A dissociação de noções visa dirimir incompatibilidades. 
Além da notável concatenação entre a resposta de RA e a resposta anterior de RB, esse fragmento transcrito sugere a presença do argumento denominado autofagia em que se estabelece a autodestruição dos enunciados postos como argumento. A autofagia se configura, nessa transcrição, quando o argumento anterior de RB afirmava, conforme interpretação de RA, que iria tratar a questão do esgoto sozinho, mas é uma argumentação que indica uma ação que não poderá ser realizada. Assim, a argumentação ou proposta de RB é inviabilizada, ou seja, seus argumentos se destroem por si, dada a sua dificuldade e ilegalidade de execução.

Nesse sentido, o argumento de autofagia necessita de interpretação discursiva (hermenêutica) para que sejam instaurados; afinal, para comprovar que determinada ideia se destrói por si e que uma ação/pessoa não deve ser seguida; faz-se necessária a fundamentação do discurso contrário.

Nota-se, com isso, que, além de evidenciar uma ideia incompatível, o argumento da autofagia vai atacar os valores do ethos retórico-discursivo de RA, que não tem sabedoria prática nem bom senso (FIORIN, 2015) quanto à questão do saneamento básico.

Além dessas categorias retóricas, verifica-se como o argumento do sacrifício se ajusta ao término de um enunciado, o que se evidencia em "tiramos dinheiro do NOSSO orçamento". Esse procedimento argumentativo fortalece o ethos do Retor A, pois aparenta novamente agradabilidade para com a população.

No final da transcrição são exibidas interrupções feitas pelo moderador do debate. Esse procedimento serve para caracterizar as peculiaridades do debate como gênero oral que deve seguir regras de produção e controle de tempo (COSTA, 2009). O moderador, pelo que se demonstra, apenas cumpre o seu papel para que a equidade entre os debatedores seja mantida, porém todo e qualquer acontecimento no gênero contribui, de uma forma ou de outra, para a persuasão do público.

\section{RESULTADOS}

A grande maioria dos argumentos aqui estudados se situam na incompatibilidade, na discordância dos fatos, nas crenças, as quais o provável auditório possui e no posicionamento político e ideológico do partido a que os debatedores pertencem. Entretanto, mesmo no movimento do contradiscurso, há projeção e desconstrução das imagens retórico-discursivas (ethos)dos debatedores. Ademais, quando fora afirmado que a persuasão textual/discursiva necessita do ethos do retor, dos argumentos produzidos por ele e do acordo social do público, volta-se para a inevitável tríade aristotélica: ethos, logos e pathos. Dessa forma, a análise de categorias retóricas nunca deve ser feita fora do seu sistema, uma vez que a 
tríade argumentativa (ethos, logos e pathos) sempre está atuando sobre as argumentações, sejam elas de teor político, jurídico, educacional etc.

Com esta análise, ficaram evidentes três observações gerais: a) o debatedor (retor) deve construir um acordo inconsciente com o seu auditório; b) esse acordo está sedimentado nos valores defendidos pela média dos componentes de cada auditório; e c) o auditório do debate político (auditório universal) acredita em fatos.

Aqui, portanto, fez-se uma aproximação entre fato social e argumento. Entretanto, os fatos, na verdade, evidenciam os argumentos; mas nem todo argumento pode ser considerado um fato, uma vez que ele pode trazer mais de um, pode também não se sustentar em um fato ou pode fazer uma ficção/exemplo/alegoria/comparação etc.

Dada essa complexidade em fazer uma análise exaustiva dos argumentos e dos fatos válidos pelo auditório social do debate político televisivo, este recorte respondeu suficientemente aos questionamentos iniciais da seguinte forma: a) os argumentos estão situados no contraditório e na projeção de ethos porque são as possibilidades disponíveis ao debatedor, dado o público do debate e os participantes imediatos dessa situação comunicativa; assim, o debatedor contradiz o candidato opositor e, nesse caminho, visa agradar seu público por meio de uma projeção positiva de sua imagem e uma descaracterização da imagem discursiva do retor adversário; e b) o ethos tem duas naturezas - a efetiva e a projetiva (MEYER, 2007), contudo, no debate, o ethos projetivo domina quase toda a discussão, pois, inevitavelmente, ao começar a exposição de seus ideais e crenças, os debatedores demonstram, textualmente, seu caráter e virtudes (ARISTÓTELES, 2011), ou seja, não interessa para o debate político televisivo as virtudes intelectuais que se restringem ao espaço de convívio particular de cada debatedor, interessam sim as virtudes conhecidas e praticadas publicamente, e essas só se manifestam pela prática da língua (enunciação).

\section{CONCLUSÃO}

Nos atos interativos do debate, os retores políticos negociam acirradamente os fatos e posicionamentos sobre esses fatos sociais. Na verdade, eles argumentam tentando persuadir o público televisivo e, para isso, relatam aquilo que possa ser aceito como verossímil por esse auditório médio.

Há, nesse processo persuasivo, as tentativas de promover as imagens discursivas dos debatedores, desvalorizando a do seu oponente e, para tanto, fundamentam suas teses por meio de argumentos que movam seu auditório social. Assim, esse auditório colabora, mesmo distante, na construção do acordo inconsciente que rege o gênero debate político televisionado. 


\section{REFERÊNCIAS}

AMOSSY, Ruth. Argumentação e Análise do Discurso: perspectivas teóricas e recortes disciplinares. Tradução de Eduardo Lopes Pires e Moisés Olímpio Ferreira. EID\&A - Revista de Estudos Integrados em Discurso e Argumentação, llhéus, n. 1, p. 129-144, nov. 2011.

ARISTÓTELES. Retórica. Trad. Edson Bini. São Paulo: Edipro, 2011.

BAUER, Martin W.; GASKELL, George. Pesquisa qualitativa com texto: imagem e som: um manual prático. Trad. Pedrinho A. Guareschi. 13. ed. Petrópolis: Vozes, 2015.

BAZERMAN, Charles. Gêneros textuais, tipificação e interação. 4. ed. Org. Ângela Paiva Dionísio e Judith C. Hoffnagel. São Paulo: Cortez, 2005.

BRAGA, Daniela. Prós e Contras: o debate político televisivo como sub-género/sub-tipo de interacção verbal, Revista Galega de Filoloxía. A Coruña: Área de Filoloxía Galega e Portuguesa - Universidade da Coruña. n.7, p 29-65, 2006. Disponível em: http://hdl.handle.net/2183/2627. Acesso em 27 dez. 2019.

COSTA, Sérgio Roberto. Dicionário dos gêneros textuais. 2. ed. Belo Horizonte: Autêntica, 2009.

FIORIN, José Luiz. Argumentação. São Paulo: Contexto, 2015.

KERBRAT-ORECCHIONI, Catherine. Les interactions verbales 1. Paris: Armand Colin, 1990. 2006 .

. Análise da conversação: princípios e métodos. Trad. Carlos P. Filho. São Paulo: Parábola Editorial,

MAINGUENEAU, Dominique. A propósito do ethos. Tradução de Luciana Salgado. In: MOTTA, A. R.; SALGADO, L. (Org.). Ethos discursivo. São Paulo: Contexto, 2008.

MARCUSCHI, Luiz Antônio. Análise da conversação. 5. ed., 6ª reimpressão. São Paulo: Editora Ática, 2003.

Produção textual, análise de gêneros e compreensão. São Paulo: Parábola Editorial, 2008.

MEYER, Michel. A retórica. Trad. Marly N. Peres. São Paulo: Ática, 2007.

PERELMAN, Chaïn; OLBRECHTS-TYTECA, Lucie. Tratado de argumentação: a nova retórica. 3. Ed. São Paulo: Martins Fontes, 2014.

PRETI, Dino (org.). Fala e escrita em questão. São Paulo: Humanitas, 2000.

REBOUL, Oliver. Introdução à Retórica. São Paulo: Martins Fontes, 1998.

SILVA, Romildo Barros da; SANTOS, Maria Francisca Oliveira. Argumentos persuasivos do debate político brasileiro. Maceió: Edufal, 2019.

SOUZA, Américo de. A persuasão. Covilhã: Universidade da Beira Interior, 2001.

VOLÓCHINOV, Valentin. Marxismo e filosofia da linguagem: problemas fundamentais do método sociológico na ciência da linguagem. Trad. Sheila Grilo. São Paulo: Editora 34, 2017. 